\title{
Oral Health Status and Treatment Needs Among the Nursing Students and Nursing Staff in Chennai
}

\author{
S Srinidhi', Preetha Elizebeth Chaly ${ }^{2}$, Navin Anand Ingle ${ }^{3}$
}

\begin{abstract}
Aim: As oral health and general health are interrelated, a preventive approach consisting of daily oral hygiene procedures and regular check-ups can stabilize progressive lesions. Aim of this study was to assess oral health status, treatment needs and attitude to oral care among nursing students and nursing staff in Chennai.

Material and Methods: A cross sectional study was carried out. Based on prevalence obtained for dental caries, it was decided to take sample size of 400 each for nursing students (final year) and nursing staff. Cluster sampling methodology was used to select samples. Each nursing college and hospital formed a cluster. Subjects were clinically examined according to WHO 1997 assessment form.

Results: Among nursing students, $17 \%$ and among nursing staff $10.3 \%$ had healthy periodontal tissue (code 0 ). Majority of nursing students and nursing staff showed high prevalence for bleeding (code 1) $45.5 \%$ among nursing students and $40.1 \%$ among nursing staff. Prevalence of shallow pockets (code 3 ) and deep pockets (code 4 ) were seen among $0.3 \%$ and $0 \%$ of nursing students and among nursing staff it was seen that about $8.8 \%$ and $0.8 \%$, had shallow and deep pockets. Mean number of sextants with code 1 or higher and code 3 or higher was more in nursing staff compared to nursing students and the difference was statistically significant. Among nursing students and nursing staff prevalence of loss of attachment was not of significance. Mean DMFT was $1.69 \pm 1.65$ among nursing students and it was higher compared to nursing staff being $1.29 \pm 1.59$ and difference was found to be statistically highly significant. Among nursing students one surface, two surfaces filling were required by $23.5 \%$ and $11.5 \%$ of subjects, respectively. Among nursing staff one surface restoration and two surface restorations were required by $9.3 \%$ and $3.0 \%$ of study subjects, respectively.
\end{abstract}

Conclusion: Present study provided data on oral health status and treatment needs of nursing students and nursing staff in Chennai. In conclusion, results of study show that periodontal disease and dental caries are not major public health problems which need immediate attention among nursing students and nursing staffs.

Keywords: Oral health status, Treatment needs, Attitudes, Nursing students, Nursing staff.

Senior Lecturer

Department of Public Health Dentistry

Meenakshi Ammal Dental College,

Maduravoyal, Chennai

Contact Author

Dr. S. Srinidhi

Srinidhiarun@ymail.com

J Oral Health Comm Dent 2012;6(2)79-85
${ }^{2}$ Professor

Department of Public Health Dentistry

Meenakshi Ammal Dental College,

Maduravoyal, Chennai

${ }^{3}$ Professor and Head

Department of Public Health Dentistry

Meenakshi Ammal Dental College,

Maduravoyal, Chennai

\section{INTRODUCTION}

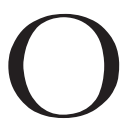

ral diseases are one of the most prevalent problems throughout the world. WHO emphasized that despite great improvements in the oral health of population in several countries, global problems still persist (1). As oral health and general health are inter related, a preventive approach consisting of daily oral hygiene procedures and regular check-ups 
can stabilize progressive lesions and prevent acute complications, so contributing to a gratifying oral function and satisfying quality of life even to age of ninety years or more (2). The high prevalence of oral disease has the greatest effect on disadvantaged population that has limited access to dental care. However common modifiable risk factors provides opportunities for reducing this burden. Health promotion program for other diseases in which life style choices are emphasized may also directly or indirectly promote oral health. In addition the development of non-dentist providers and various models of health care delivery have developed in response to oral disease problems (3). Currently across the world, non - dentist providers are being educated and used to perform many procedures that are restricted to the dentist in many health care systems.

Care of the oral cavity is considered to be one of the most basics of nursing, but the importance given to oral health care by the nursing students is limited, although oral care is a part of every introductory programme. Experts in the field rarely teach it and it is found that qualified nursing staff and nursing students lack adequate knowledge related to oral health resulting in, inadequate oral care of patients on medical wards (4). In nurses training, as oral care is often left to the patients themselves and it is a task that is largely delegated to untrained staff or considered to be the responsibility of dental staff members (5). Barriers to oral hygiene care are low priority, the carers regard it as an unwelcome chore, nursing staffs consider it as an unpleasant task, many community carers felt it as problematic (6).

Most of the non-ambulatory patients depend on nurses for their maintenance of oral hygiene. While poor oral health is not an inevitable consequence of ageing, extrinsic factors like systemic diseases, medication and lack of access to treatment can damage oral health status. However there is considerable evidence to show that caregivers such as nurses are neglecting oral health care needs (6). Hence every nursing student should be aware of his or her own power of maintaining good dental health and also made aware of the implications of inadequate dental care. Improving their knowledge and attitude related to oral health will result in adequate oral care for patients on medical wards.

\section{AIM AND OBJECTIVES}

To assess the oral health status and treatment needs among final year nursing students and nursing staff in Chennai.

\section{Objectives}

To measure indicators of periodontal status which includes bleeding, calculus, shallow pockets, deep pockets and loss of attachment among Nursing students and Nursing staff in Chennai and to the assess caries experience among Nursing students and Nursing staff. To assess the treatment needs among Nursing students and Nursing staff and to determine prosthetic status and prosthetic needs and comparing the data's obtained between final year nursing students and nursing staff.

\section{MATERIALS AND METHODS}

An epidemiologic survey was conducted to assess the oral health status and treatment needs among final year nursing students and nursing staff in Chennai. Data was collected through a survey which included clinical examination. Approval from the authorities was obtained by visiting the concerned hospital and colleges. Ethical committee clearance was obtained from Institutional Review Board of Meenakshi University. For the pilot study, cluster sampling methodology was followed. The minimum sample size was decided at 50 each, for nursing students (final year) and nursing staff respectively. From the list of nursing colleges and hospitals, randomly two nursing colleges were selected. A total of 98 nursing students and 72 nursing staff were examined following a cluster sampling with a total sample size of 170 . The selected subjects were examined according to WHO Basic Oral Health Assessment (1997) (7). All nursing students and nursing staff were examined by a single examiner seated on a chair and examined under natural light using standardized instruments. As dental caries was found to be the most common disease in both the groups (nursing students and nursing staff) the sample size was calculated using the prevalence of dental caries with $99 \%$ power. The minimum sample sizes each, for both nursing students (final year) and nursing staff was 355 . It was decided to examine a population of 400 nursing staff and 400 nursing students each, so as to increase the accuracy of the study. Cluster sampling methodology was used to select the samples. Each nursing college

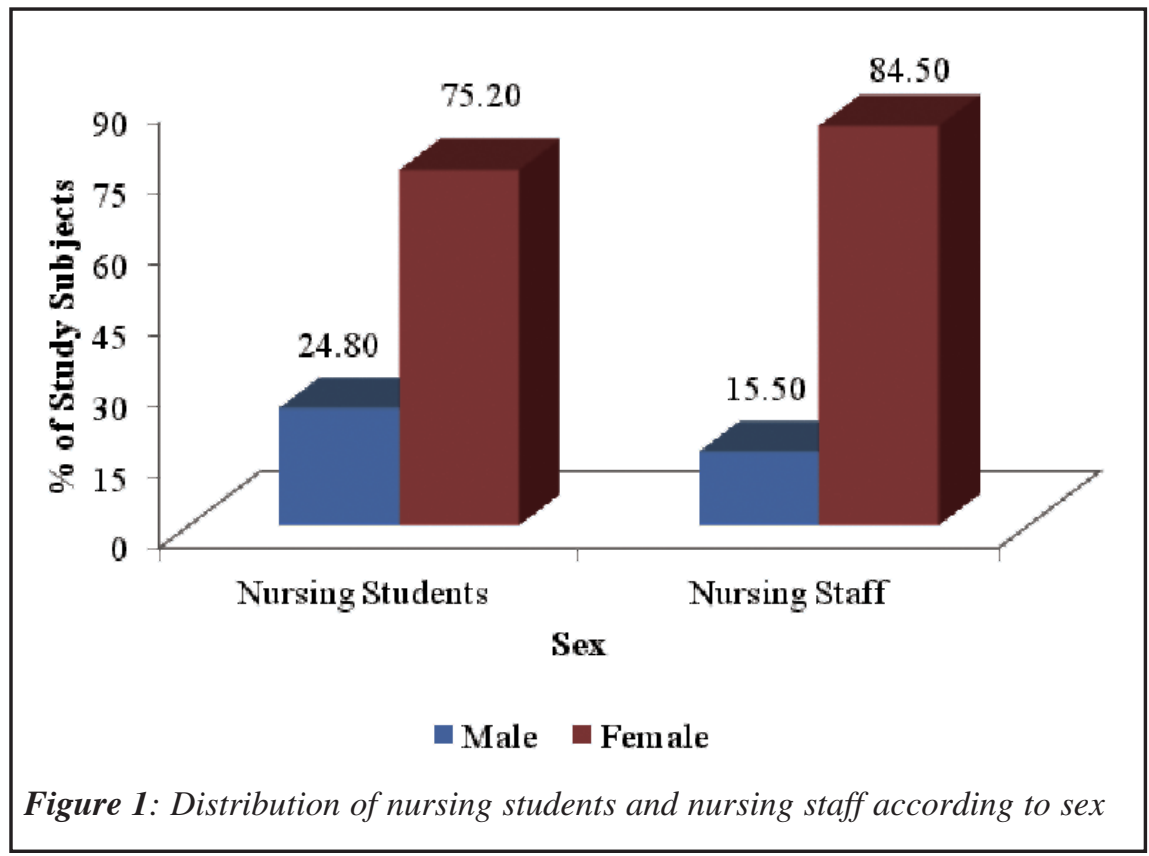


Table 1: Distribution of prevalence of study subjects according to different periodontal conditions by highest score

\begin{tabular}{|lrrrrr|}
\hline CPI Scores & Nursing Students & Nursing Staff & P- Value \\
& N & $\%$ & N & $\%$ & \\
\hline Healthy (O) & 68 & 17 & 41 & 10.3 & \\
Bleeding (1) & 182 & 45.5 & 161 & 40.1 & \\
Calculus (2) & 149 & 37.2 & 160 & 40.0 & P $<0.001^{+++}$ \\
Periodontal pocket 4 $-5 \mathrm{~mm}(3)$ & 1 & 0.3 & 35 & 8.8 & \\
Periodontal pocket 6 mm or more (4) & 0 & 0 & 3 & 0.8 & \\
Total & 400 & $\mathbf{1 0 0}$ & $\mathbf{4 0 0}$ & $\mathbf{1 0 0}$ & \\
${ }^{+++} \mathrm{P}<0.001, \quad$ Statistically very highly significant & & & & & \\
\hline
\end{tabular}

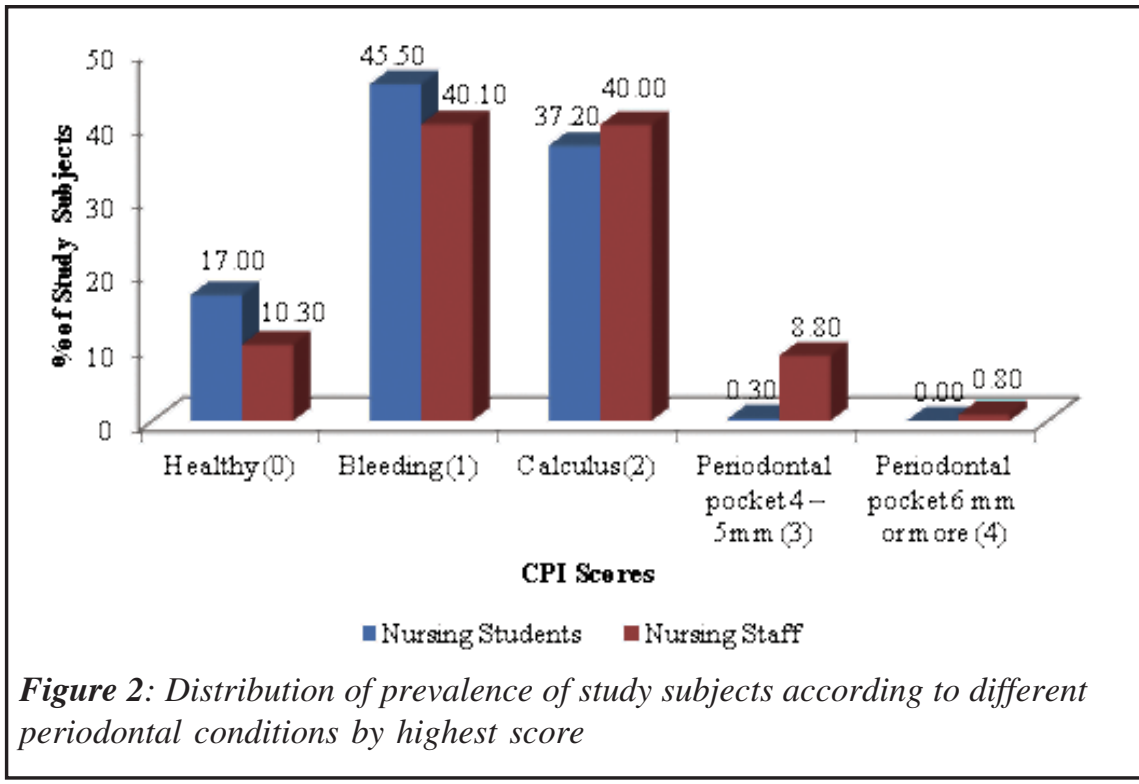

and hospital formed a cluster. Inclusion criteria were the nursing college and hospitals should be recognized by the Government of India and the nursing colleges were included only if they had B.sc nursing. Clinical examination was performed according to WHO basic oral health assessment form 1997. Examinations were performed in the recording forms using a mouth mirror, CPI probes and other instruments used were the chip blowers and tweezers.

\section{Statistical analysis}

Qualitative data - For comparing percentages Pearson's Chi Square test was used. Quantitative data-For comparison of two groups, Independent ' $t$ ' test or Mann

Table 2: Mean number of sextants affected by different periodontal conditions on cumulative basis among the study subjects

\begin{tabular}{|lccrrr|}
\hline CPI Scores & Nursing Students & \multicolumn{2}{c}{ Nursing Staff } & P- Value \\
& Mean & SD & Mean & SD & \\
\hline Healthy $(0)$ & 2.14 & 2.25 & 2.20 & 1.97 & $P>0.05^{*}$ \\
Code 1 or higher & 3.57 & 2.11 & 4.05 & 2.12 & $P<0.01^{++}$ \\
Code 2 or higher & 1.03 & 1.54 & 1.28 & 1.78 & $P>0.05^{*}$ \\
Code 3or higher & 0.02 & 0.20 & 0.13 & 0.56 & $P<0.001^{+++}$ \\
Code 4 & 0.00 & 0.00 & 0.01 & 0.15 & $P>0.05^{*}$ \\
& & & & & \\
${ }^{++} \mathrm{P}<0.01$, Statistically highly significant & & & & \\
${ }^{+++} \mathrm{P}<0.001$, Statistically very highly significant & & & & \\
${ }^{*} \mathrm{P}>0.05$, Statistically not significant & & & & & \\
\hline
\end{tabular}

Whitney's test was used and for comparing more than two groups Analysis of Variance test (ANOVA) or Kruskal Wallis test was used.

\section{RESULTS}

It was found that among the 800 study subjects, 400 were nursing students and 400 were nursing staffs. $99(24.8 \%)$ were males and $301(75.2 \%)$ were females among the nursing students. Among the nursing staff, 62 (15.5\%) were males and $338(84.5 \%)$ were females. (Figure 1).

Among the nursing students, 68 (17\%) had healthy periodontal tissue (code 0), 182 (45.5\%) had bleeding (code 1), 149 (37.2\%) had calculus (code 2), $1(0.3 \%)$ had shallow pockets (code 3) as their highest score. No subjects among nursing students were found with deep pockets. Among the nursing staff, $41(10.3 \%)$ had healthy periodontal tissues (code0), 161 (40.1\%) had bleeding (code 1), 160 (40.0\%) had calculus (code 2), 35 (8.8\%) had shallow pockets (code 3 ) and $3(0.8 \%)$ had deep pockets (code 4$)$ as their highest score. The difference noted in the prevalence of study subjects according to different periodontal conditions by highest score between the nursing students and nursing staff were statistically very highly significant. $(\mathrm{P}<0.001)$.(Table 1, Figure 2) Among the nursing students the mean number of healthy sextants (code 0), bleeding (code 1) or higher, calculus (code 2) or higher, shallow pockets (code 3 ) or higher, deep pockets (code 4) were $2.14 \pm 2.25$, $3.57 \pm 2.11, \quad 1.03 \pm 1.54, \quad 0.02 \pm 0.20$, $0.00 \pm 0.00$ respectively (Table 2 ).

Among the nursing staff number of sextants with healthy (code 0), bleeding (code 1) or higher, calculus (code 2) or higher, shallow pockets (code 3 ) or higher and deep pockets (code 4) were 2.20 \pm 1.97 , $4.05 \pm 2.12,1.28 \pm 1.78,0.13 \pm 0.56$, $0.01 \pm 0.15$ respectively. The differences noted in the mean number of sextants between the nursing students and nursing staff for (code 1) or higher was found to be statistically highly significant $(\mathrm{P}<0.01)$ and very highly significant $(\mathrm{P}<0.001)$ for (code 3) or higher. (Table 3). For the prevalence of study subjects according to loss 


\section{Table 3: Caries experience among the study subjects}

\begin{tabular}{|c|c|c|c|c|c|}
\hline Status & $\begin{array}{l}\text { Nursing } \\
\text { Mean }\end{array}$ & $\begin{array}{c}\text { Students } \\
\text { SD }\end{array}$ & $\begin{array}{l}\text { Nursin } \\
\text { Mean }\end{array}$ & $\begin{array}{r}\text { Staff } \\
\text { SD }\end{array}$ & P- Value \\
\hline Decayed (D) & 1.23 & 1.45 & 1.06 & 1.38 & $P>0.05^{*}$ \\
\hline Missing (M) & 0.46 & 0.64 & 0.19 & 0.45 & $P<0.001^{+++}$ \\
\hline Filled $(F)$ & 0.01 & 0.15 & 0.55 & 0.33 & $P<0.05^{+}$ \\
\hline DMFT & 1.69 & 1.65 & 1.29 & 1.59 & $P<0.001^{+++}$ \\
\hline \multicolumn{6}{|c|}{$\begin{array}{l}{ }^{+} P<0.05 \text {, Statistically significant } \\
{ }^{+++} P<0.001 \text {, Statistically very highly significant } \\
{ }^{P}>0.05 \text {, Statistically not significant }\end{array}$} \\
\hline
\end{tabular}

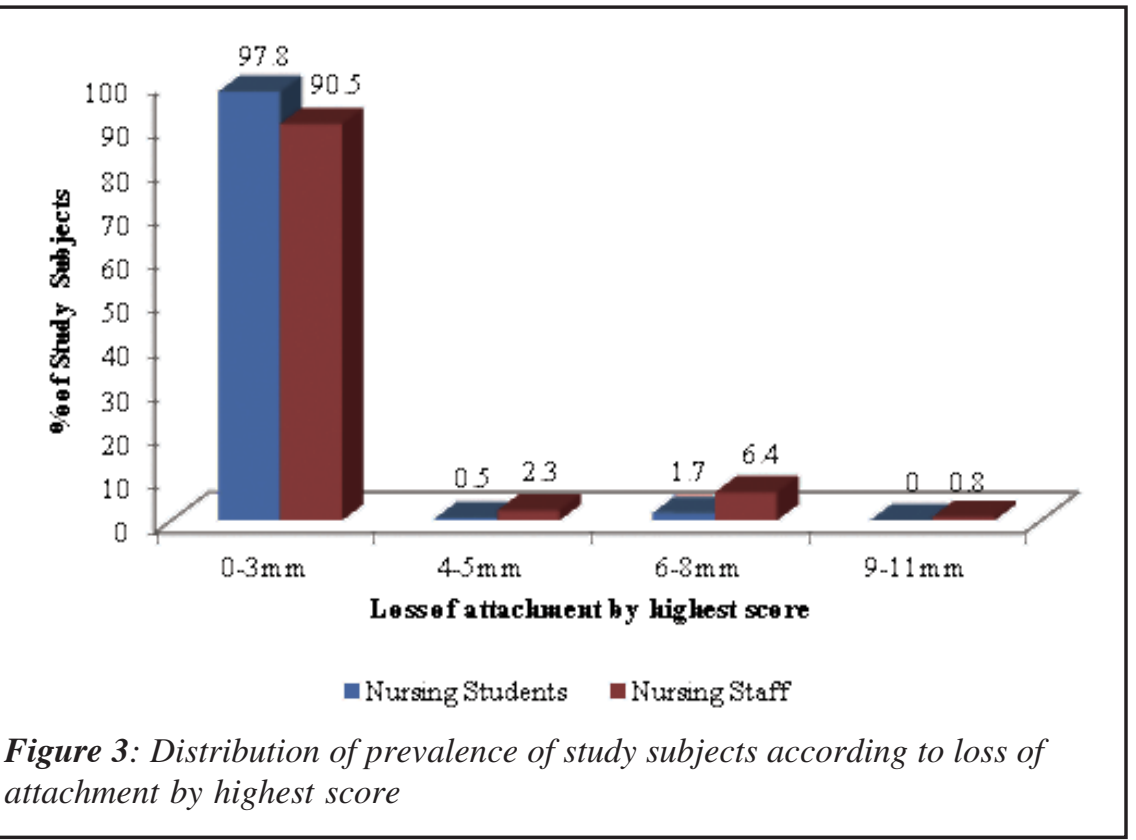

of attachment by highest scores among the nursing students, $391(97.8 \%)$ had loss of attachment of $0-3 \mathrm{~mm}$ (code 0$), 2$ $(0.5 \%)$ had loss of attachment of $4-5 \mathrm{~mm}$ (code 1), $7(1.7 \%$ ) had loss of attachment of 6-8 $\mathrm{mm}$ (code 2). Code 3 was not observed among nursing student. (Figure 3) Among the nursing staffs, $362(90.5 \%)$ had loss of attachment of $0-3 \mathrm{~mm}$ (code $0), 9(2.3 \%)$ had loss of attachment of $4-5$ mm (code 1), 26 (6.4\%) had loss of attachment of 6-8 mm (code 2), 3 (8\%) had loss attachment of $9-11 \mathrm{~mm}$ (code 3). The differences noted in the prevalence of subjects with loss of attachment between both groups were found to be statistically very highly significant $(\mathrm{P}<0.001)$. (Figure 3 ). Among the nursing students the mean number decayed teeth was $1.23 \pm 1.45$ and among the nursing staff it was found to

Table 4: Mean number of teeth requiring various modalities of treatment among the study subjects

\begin{tabular}{|c|c|c|c|c|c|}
\hline Treatment needed & $\begin{array}{l}\text { Nursing } \\
\text { Mean }\end{array}$ & $\begin{array}{c}\text { Students } \\
\text { SD }\end{array}$ & $\begin{array}{l}\text { Nursing } \\
\text { Mean }\end{array}$ & $\begin{array}{r}\text { Staff } \\
\text { SD }\end{array}$ & P- Value \\
\hline One surface filling & 0.70 & 1.06 & 0.23 & 0.65 & $\mathrm{P}<0.001^{+++}$ \\
\hline Two surface filling & 0.45 & 0.73 & 0.13 & 0.44 & $\mathrm{P}<0.001^{+++}$ \\
\hline Pulp care & 0.26 & 0.68 & 0.05 & 0.28 & $\mathrm{P}<0.001^{+++}$ \\
\hline Extraction & 0.08 & 0.32 & 0.06 & 0.41 & $P>0.05^{*}$ \\
\hline \multicolumn{6}{|c|}{${ }^{+++} P<0.001$, Statistically very highly significant } \\
\hline
\end{tabular}

be 1.06 \pm 1.38 . This difference noted between the nursing students and nursing staff was not found to be statistically significant $(\mathrm{P}>0.05)$. The mean number of missing teeth was $0.46 \pm 0.64$ among the nursing students and among the nursing staff it was $0.19 \pm 0.45$. This difference was found to be statistically very highly significant $(\mathrm{P}<0.001)$. The mean number of filled teeth among the nursing students was $0.01 \pm 0.15$ and among the nursing staff it was $0.05 \pm 0.33$. This difference noted was statistically significant $(\mathrm{P}<0.05)$. The mean DMFT among the nursing students was $1.69 \pm 1.65$ and among nursing staff it was 1.29 \pm 1.59 . This difference noted was found to be statistically very highly significant $(\mathrm{P}<0.001)$ (Table 3). Mean number of teeth requiring various modalities of treatment among the study subjects requiring one surface filling, two surface filling, pulp care and extraction were more in nursing students being $0.70 \pm 1.06,0.45 \pm 0.73$, $0.26 \pm 0.68,0.08 \pm 0.32$ compared to the nursing staffs being $0.23 \pm 0.65,013 \pm 0.44$, $0.05 \pm 0.28,0.06 \pm 0.41$ respectively. Differences noted in the mean number of teeth between two groups was statistically very highly significant for one surface restoration, two surface restoration and pulp care $(\mathrm{P}<0.001)$ and not statistically significant for extraction ( $\mathrm{P}>0.05)$. (Table 4, Figure 4)

\section{DISCUSSION}

Many people with disabilities have a limited capacity to carry out oral hygiene measures and are thus dependent on the skills and motivation of their carers for routine mouth care (8). Principle objective of mouth care is to maintain the mouth in good oral condition that is comfortable, clean, moist and free of infections- states Watson (1989) (9). Unfortunately oral health problems can be overshadowed by other needs which are perceived to be more urgent and obvious by care givers. Although mouth care is a part of every introductory nursing programme, it is rarely taught by the experts in the field and in the wards it's the most junior nurse who is often asked to undertake mouth care. Often it is the trained nurses on the wards who teach oral health care to untrained nurses and health care assistants. This has 


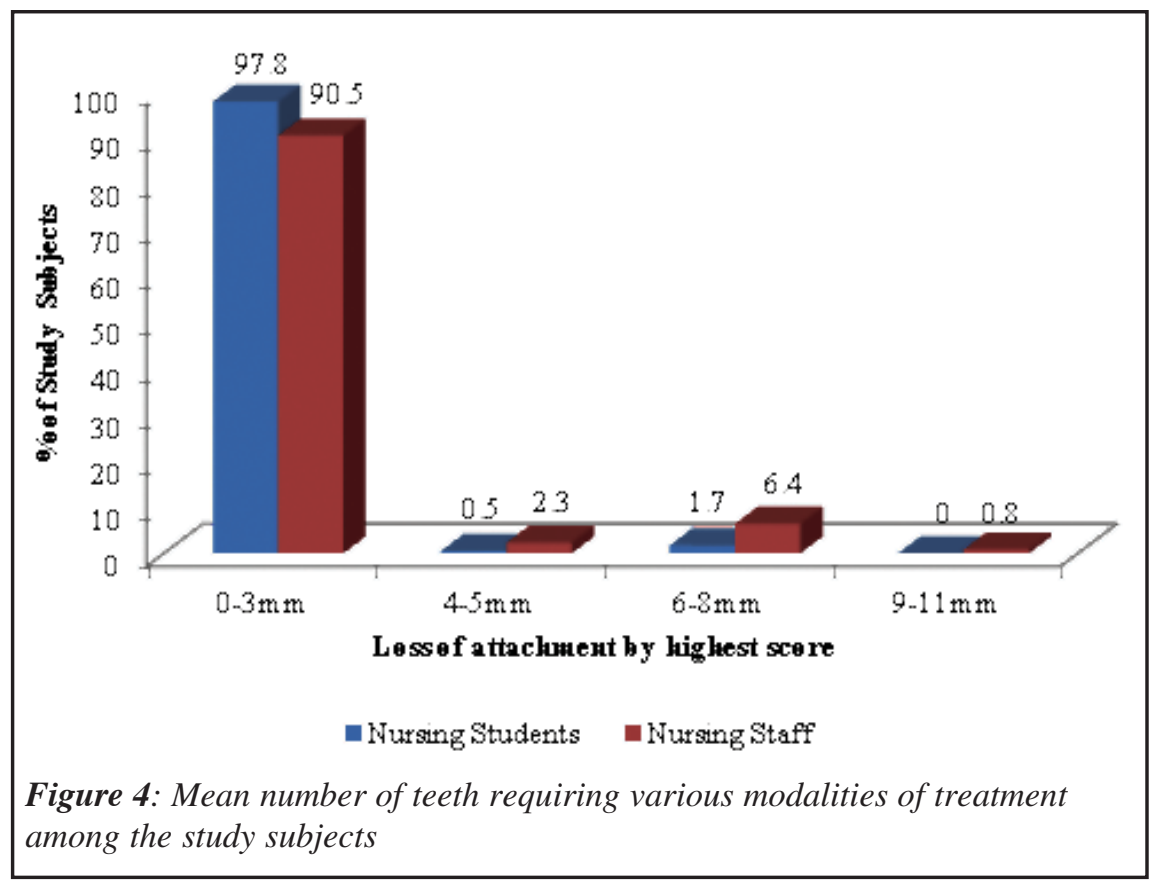

serious ramifications if the trained nurses lack the appropriate knowledge. Conditions such as oral candidiasis, denture stomatitis, denture irritation hyperplasia and traumatic ulceration may also occur as a result of oral neglect (10). It is therefore important that health care professionals caring for patients in hospitals and other venues have core knowledge of the dental care needs of their patients.

According to prevalence of the indicators of periodontal conditions by highest score

Among the nursing students and nursing staffs about $68(17 \%)$ and $41(10.3 \%)$ had healthy periodontal tissue and about 182 (45.5\%), 161 (40.1\%) had bleeding, 149 $(37.2 \%)$ and $160(40.0 \%)$ had calculus, 1 $(0.3 \%)$ and $35(8.8 \%)$ had shallow pockets respectively. About $3(0.8 \%)$ among the nursing staffs had deep pockets. In a study by Coelho RS et al (11) in adults from the city of recife Brazil a few presented score 1 (gingival bleeding) and score 0 (periodontal health) as the highest CPI score that is $10.3 \%$ and $10.7 \%$ respectively. Most subjects presented score $2(61.8 \%)$ or $3(15.2$ $\%$ ) as the highest CPI score and only a small proportion were classified as score $4(2.0 \%)$. In a study by Kawamura $\mathrm{M}$ et al (12) on Japanese adults only $1 \%$ of the total samples were found with healthy periodon- tium (Code 0), 9\% recorded bleeding on probing (Code 1). Calculus (Code 2) was the most prevalent condition with $51 \%$ of subjects recording this code as the worst condition, followed by shallow pockets (Code 3) in 30\%, and deep pockets (Code 4) in $9 \%$ of the sample. In a study by Brown LJ et al (13) in the employed US population between the ages of 18 64years, periodontal pockets 4-6mm deep were observed in $13.4 \%$ of the employed population. This shows that periodontal health is better in nursing students and nursing staff compared to the adults of Brazil, Japan and US. Being in the paramedical field with increased access to health awareness programmes the nursing students and nursing staff would have been able to maintain better periodontal health compared to other adults in general population.

\section{According to mean number of sex- tants affected by different peri- odontal conditions on cumulative basis}

Among the nursing students the mean number of sextants with healthy (code 0 ), bleeding (code 1) or higher, calculus (code 2) or higher, shallow pockets (code 3 ) or higher and deep pockets (code 4) were 2.14 $\pm 2.25,3.57 \pm 2.11,1.03 \pm 1.54,0.02 \pm 0.20$, $0.00 \pm 0.00$ respectively and among nursing staffs the mean number of sextants with healthy (code 0 ), bleeding (code 1) or higher, calculus (code 2) or higher, shallow pockets (code 3) or higher and deep pockets (code 4) were 2.20 $\pm 1.97,4.05$ $\pm 2.12,1.28 \pm 1.78,0.13 \pm 0.56,0.01 \pm 0.15$ respectively. In a study by Falouh (14) among 1542 Syrian Adults of age group $35-44$, for mean number of sextants, 1.8 were coded as (code 0 ) healthy sextants and 3.8 were coded as (code 1) or higher, 2.6 were coded as (code 2 ) or higher, 0.5 were coded as (code 3) or higher, and 0.1 were coded as (code 4). In another study by Khattib YA et al (14) for Ministry of health, among 327 Syrian adults of age group 3544 , for mean number of sextants, 1.9 were coded as healthy (code 0), 3.7 were coded as bleeding (code 1) or higher, 1.8 were coded as calculus (code 2) or higher, 0.4 were coded as shallow pockets (code 3 ) or higher, and 0.2 were coded as deep pockets ( code 4 ). When compared with the present study the above findings were higher for bleeding (code 1) or higher, calculus (code 2 )or higher, shallow pockets (code 3) or higher and deep pockets (code 4) compared to nursing students and nursing staffs. while shallow pockets (code 3) or higher and 0.2 were coded as deep pockets (code 4). When compared with the present study the above findings were higher for bleeding (code 1 ) or higher, calculus (code 2 ) or higher, shallow pockets (code 3 ) or higher and deep pockets (code 4 ) compared to the nursing students and nursing staff. This might be because of increased awareness among the nurses as they are in a paramedical field which has enabled them to maintain better oral health.

\section{According to the prevalence of loss of attachment}

Among the nursing students 97.8\% (391) had $0-3 \mathrm{~mm}$ of loss of attachment and 2 $(0.5 \%)$ had $4-5 \mathrm{~mm}$ of loss of attachment, $7(1.7 \%)$ had $6-8 \mathrm{~mm}$ loss of attachment, $0(0.0 \%)$ had $9-11 \mathrm{~mm}$ loss of attachment among the nursing students. Among the nursing staffs $90.5 \%$ (362) had 0-3 mm of loss of attachment and $9(2.3 \%)$ had 4-5 $\mathrm{mm}$ of loss of attachment, $26(6.4 \%) \mathrm{had}$ 6-8 mm loss of attachment and $3(0.8 \%)$ had $9-11 \mathrm{~mm}$ loss of attachment. In a 
study by Joseph J et al (15) among Hassan Population $9.7 \%$ had $4-5 \mathrm{~mm}, 5.1 \%$ had 6-8 $\mathrm{mm}$ and $2.2 \%$ had $9-11 \mathrm{~mm}$ of loss of attachment. When compared with the above studies prevalence of loss of attachment is lower in the nursing staff and nursing students. As more than $50 \%$ of the nursing students and nursing staff use to visit the dentist regularly for dental checkup, early detection and correction of periodontal problems could have led to better periodontal health.

\section{Caries experience of subjects}

Among the total study subjects of 800 which comprised both the nursing students (400) and the nursing staffs (400) the mean DMFT, mean DT, mean MT and mean FT was 1.23 $\pm 1.45,0.46 \pm 0.64$, $0.01 \pm 0.15$ and $1.69 \pm 1.65$, respectively among the nursing students and among the nursing staff it was $1.06 \pm 1.38$, $0.19 \pm 0.45,0.05 \pm 0.33$, and $1.29 \pm 1.59$, respectively. This suggests that the nursing students had more decayed, missing teeth and the mean DMFT compared to the nursing staffs. During student life the tendency to have fast food, confectionaries, beverages are more than in matured adult life. This added with personal negligence of oral health might have increased the mean DMFT, DT and MT in the nursing students compared with nursing staff. The missing component which is less in nursing staff might have been because with age they would have gained more knowledge about the importance of oral health and would have gone in for restoration of teeth instead of extraction. In a study by Sendhilkumar et al (16) on the people of east coastal areas of Chennai, the mean number of decayed teeth was 3.07 and the mean numbers of DMFT was 4.5 which was lower than the present study. In a another survey carried out by Khattib YA et al (14) for Ministry of health in Syria, the DMFT of 35-44 age group was 11.2 which is very high when compared to the present study. In the present study the mean DMFT was $1.37 \pm 0.19$ for nursing staff in the age group 35-39 years. Among the nursing students, mean number of missing teeth among males were $0.35 \pm 0.57$ and females had $0.49 \pm 0.65$ respectively and among the nursing staffs the mean number of missing teeth among males was about $0.18 \pm 0.4$ and females was about $0.20 \pm 0.46$. In a study by Jovino-Silveira $\mathrm{RC}$ et al17 among Brazilian population, tooth loss due to caries was more frequent in males $(65.0 \%)$ than in females $(61.9 \%)$ whereas in the present study it was more frequent in females compared to males. In a study by Hamasha A et al (18) among the adult population of the Irbid Governate of Jordan among 18 years and over the mean number of coronal surfaces with fillings was $8.0 \pm 6.9$ which is very high when compared with the present study being $0.01 \pm 0.15$ among the nursing students and $0.05 \pm 0.33$ among the nursing staffs. This might be due to the increased awareness and availability of dental public services in Jordan.

\section{Treatment needs of subjects}

Mean number of teeth requiring one surface and two surface filling were more in both nursing students and nursing staff compared to the need for pulp care and extraction. This shows that most of the study subjects were suffering from dental disease which can be corrected by diagnosis and prompt treatment. The use of preventive modalities would further help to improve the dental status if used appropriately.

\section{SUMMARY AND CONCLUSION}

The aim of the study was to assess the oral health status and, treatment needs to oral health care among the nursing students and nursing staffs in Chennai. The study was conducted in various hospitals and nursing colleges.

- Majority of the nursing students and nursing staff showed high prevalence of bleeding, (45.5\%) among the nursing students and (40.1\%) among the nursing staffs.

- Prevalence of shallow pockets and deep pockets were seen among $0.3 \%$ and $0 \%$ of the nursing students, respectively. Among nursing staffs it was $8.8 \%$ and $0.8 \%$, respectively.

- Mean number of sextants with code 1 or higher and code 3 or higher was more in nursing staff compared to nursing students and the difference was statistically significant.

- Mean DMFT was 1.69 1.65 among the nursing students and was higher compared to nursing staff being $1.29 \pm 1.59$ and the difference was found to be statistically highly significant.

- The most commonly needed treatment modality was one surface restoration being $23.5 \%$ among the nursing students and $9.3 \%$ among the nursing staffs

In conclusion the results of the study showed that periodontal disease and dental caries are not a major public health problems which need immediate attention among nursing students and nursing staffs. Majority of the study population had bleeding and calculus. Regular dental check -ups and practice of routine oral hygiene procedures will enable them to lead a more healthier life. Increased exposure to dental health education through dental professionals will enable them to improve their attitude and behavior towards their patients on oral health care.

\section{RECOMMENDATIONS}

Following are the recommendations.

- The nursing council in consultation with dental profession should develop instructions in providing oral care to the patients by nurses as a part of their curriculum.

- Nurses should use oral assessment guides. This would improve awareness of the importance of dental health. More assessment would take place and the oral assessment guide would provide a facility for documentation.

- Presence of a dentist is important in training the nurses for various oral health care techniques and also in assessing oral health.

\section{REFERENCES}

1. Paul Erick Peterson, Denis Bourgeois and Hiroshi Ogawa et al. The global burden of oral diseases and risk to oral health. Bulletin of the World Health Organization 200 ; 83 (9) :661-669.

2. R. Ferro, A. Besostri and L. Strohnenger et al. Oral health problems and needs in nursing home residents in northern Italy. Community Dental Health 2008;(25):231- 
236.

3. Jill Mason. Concepts in dental public health

4. Longhrust RH. A cross sectional study of the oral health care. A competitive study of registered nurses, nursing assistants and home care aides. Gerodontology 1997 ; July $141: 28-32$

5. D.R Eadie and Schou. L. An exploratory study of barriers to promoting oral hygiene through carers of elderly people. Community Dental Health 1992 ;9 343348.

6. G. Radha, K.H Shaikh Hyder Ali, Pushpanjali. Knowledge, attitude and practice of oral health among nursing staff and nursing students of banglore city. Journal of Indian Association of Public Health Dentistry. 2008 (11):17-21.

7. World Health Organization. Oral Health Surveys. Basic Methods. $4^{\text {th }}$ ed. Geneva :WHO, 1997.

8. J.C Weeks and J.Fiske. Oral care of people with disability : a qualitative exploration of the views of nursing staff.
Gerodontology $1994 ; 11$ (1) :13-17.

9. Rachel Adams. Qualified nurses lack adequate knowledge related to oral health, resulting in inadequate oral care of patients on medical wards. Journal of Advanced Nursing 1996;24:552-560.

10. A.J Preston, S, Punekar, MA Gosney. Oral care of elderly patients :nurses knowledge and views. Post Graduate Medical Journal 2000;76 :89-91.

11. Coelho, Estela Santos Gusmao, Renata Cimoes Jovino Silveira, Arnaldo de Franca Caldas Junior. Profile of periodontal conditions in a barazilian adult population. Oral Health and Preventive Dentistry 2008 ;6:139-144.

12. M.Kawamura, H.Sasahara, K.Kawabata, Y.Iwamoto, K.Konishi, F.A.C Wright. Relationship between CPITN and oral health behavior in Japanese adults. Australian Dental Journal 1993 ; 38 (5):381-388

13. L.Jackson Brown, Richard. C.Oliver, Harald Loe. Evaluating periodontal status of US employed adults. Journal of American Dental Association $1990 ; 121$ :227-230

14. Beiruti. N,Taifour D, Helderman WHP, Frenken JE. A review of oral health status in Syria. International Dental Journal. 2000;50:395- 399.

15. J. Joseph, SB.Javali, K.V.V Prasad. Oral health in the district of Hassan, Karnataka state - An epidemiological study. Journal of Indian Association of Public Health Dentistry. 2002:15-17.

16. B. Sendhil Kumar, K.V Arun. Oral health status in east coastal areas of Chennai, Tamilnadu. Journal of Indian Association of Public Health Dentistry 2002;11-15.

17. Jovino Silveira RC, Arnaldo de Franca Caldas Junior, Eliane Helena Alvium de Souza, Estela Santos Gusmao. Primary reasons for tooth extraction in Brazilian adult population. Oral Health and Preventive Dentistry. 2005;3(3):153-157.

18. A.A Hamasha, R.A Safadi. Coronal caries experience in dentate Jordanian adults. Community Dental Health 2008;25:50-54. 